\title{
Anisotropic dispersive Henry problem
}

\author{
Elena Abarca *, Jesús Carrera, Xavier Sánchez-Vila, Marco Dentz \\ Department of Geotechnical Engineering and Geoscience, Technical University of Catalonia, Barcelona, Spain \\ Received 20 May 2005; received in revised form 14 August 2006; accepted 16 August 2006 \\ Available online 2 October 2006
}

\begin{abstract}
The Henry problem has played a key role in our understanding of seawater intrusion into coastal aquifers and in benchmarking density dependent flow codes. This paper seeks to modify Henry's problem to ensure sensitivity to density variations and vertical salinity profiles that resemble field observations. In the proposed problem, the "dispersive Henry problem", mixing is represented by means of the traditional Scheidegger dispersion tensor (dispersivity times water flux). Anisotropy in the hydraulic conductivity is acknowledged and Henry's seaside boundary condition of prescribed salt concentration is replaced by a flux dependent boundary condition, which represents more realistically salt transport across the seaside boundary. This problem turns out to be very sensitive to density variations and its solution gets closer to reality. However, an improvement in the traditional Henry problem (gain in sensitivity and realism) can be also achieved if the value of the Peclet number is significantly reduced.

Although the dispersive problem lacks an analytical solution, it can shed light on flow in coastal aquifers. It provides significant information about the factors controlling seawater penetration, width of the mixing zone and influx of seawater. The width of the mixing zone depends basically on dispersion with longitudinal and transverse dispersion controlling different parts of the mixing zone but displaying similar overall effects. Toe penetration is mainly controlled by the horizontal permeability and by the geometric mean of the dispersivities. Finally, transverse dispersivity and the geometric mean of the hydraulic conductivity are the leading parameters controlling the amount of saltwater that enters the aquifer.
\end{abstract}

(C) 2006 Elsevier Ltd. All rights reserved.

Keywords: Seawater intrusion; Henry problem; Dispersion; Transverse dispersion; Anisotropy

\section{Introduction}

\subsection{The Henry problem}

An abstraction of the saltwater intrusion problem in a vertical cross-section perpendicular to the coast line was introduced by Henry [1]. The solution achieved its objective as it helped to shape the basic hydraulic concepts of seawater intrusion. The conceptual model is that of a confined aquifer with homogeneous isotropic hydraulic conductivity. The original boundary conditions (BC) were defined in terms of stream functions. Fig. 1 presents the classic way to represent these $\mathrm{BC}$ in numerical models: no-flow

\footnotetext{
* Corresponding author. Tel.: +34 93 4011820; fax: +34 934017251.

E-mail address: elena.abarca@upc.edu (E. Abarca).
}

along the top and bottom boundary, specified freshwater flux along the inland boundary and prescribed saltwater hydrostatic pressure along the seaside boundary. The Henry problem considers advection and diffusion (no dispersion). This configuration leads to a characteristic stable density stratification with denser saltwater encroaching below freshwater. Henry [1] provided a semi-analytical solution for this problem configuration. His solution was revised and improved by Segol [2] and Borisov et al. [3]. The semi-analytical solution in these studies was given as an infinite-series solution. More recently, Dentz et al. [4] proposed a perturbation method solution to this problem.

The Henry problem solution depends on three dimensionless parameters:

$a=\frac{q_{\mathrm{b}}}{K \epsilon} \quad b=\frac{D_{\mathrm{m}} \phi}{q_{\mathrm{b}} d} \quad \xi=\frac{L}{d}$ 


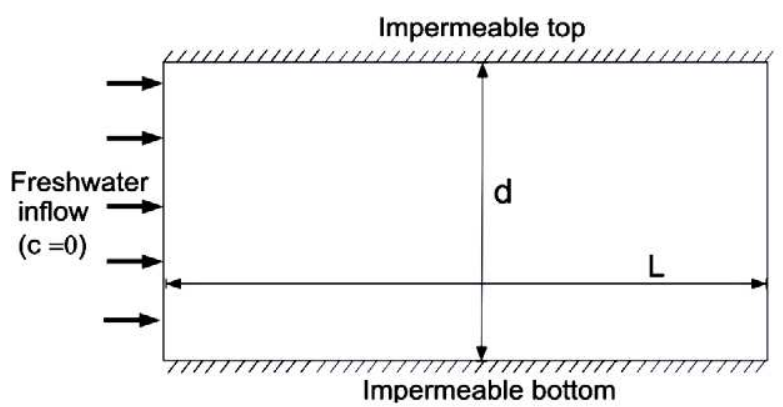

Hydrostatic

pressure

$(\mathrm{c}=1)$
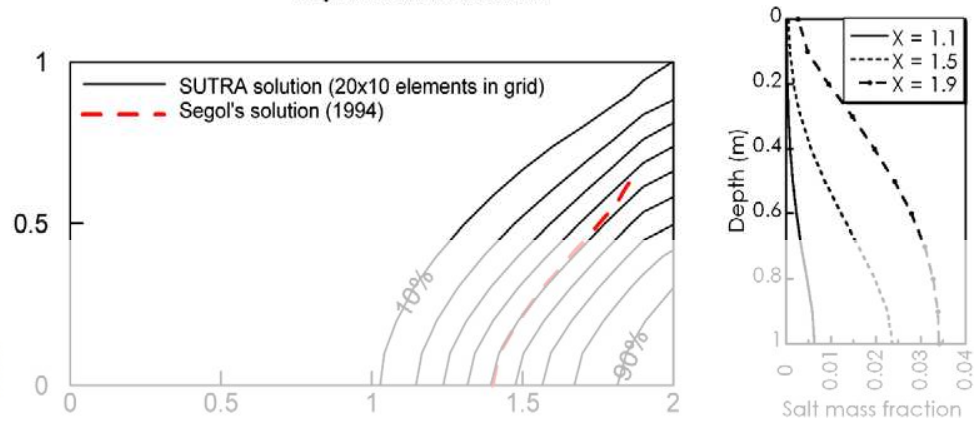

Fig. 1. Henry problem domain and boundary conditions [1]. Numerical solution in terms of the concentration distribution and some vertical salinity profiles calculated at $x=1.1,1.5$ and 1.9 .
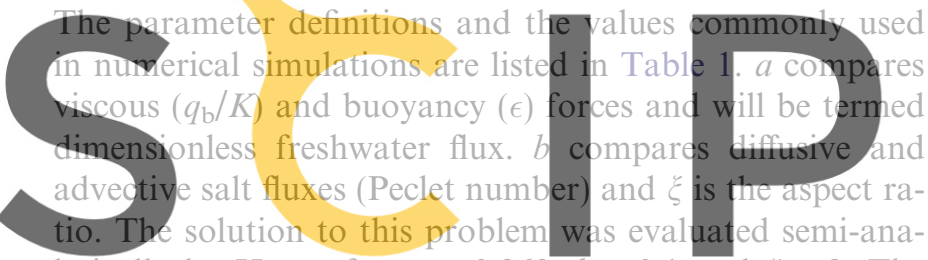

lytically by Henry for: $a=0.263, b=0.1$ and $\xi=2$. The

Henry problem has become a classic benchmark test case

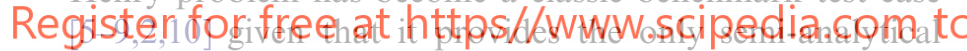
solution to boundary conditions that resemble seawater intrusion. However, discrepancies arise from the way different authors interpreted the Henry problem yielding disparate results. Croucher and O'Sullivan [10] and Bues and Oltean [11] discussed some of these discrepancies.

\section{- Inland boundary condition.}

Henry's original BC prescribed the gradient of the stream function to be parallel to the vertical boundaries. The difference between the specified values of stream

Table 1

Original parameters used in the Henry problem

\begin{tabular}{lll}
\hline Parameter & Value & \\
\hline$L$ & $2 \mathrm{~m}$ & Domain length \\
$d$ & $1 \mathrm{~m}$ & Domain thickness \\
$\phi$ & 0.35 & Porosity \\
$K$ & $1.0 \mathrm{E}-2 \mathrm{~m} / \mathrm{s}$ & Hydraulic conductivity (isotropic) \\
$D_{\mathrm{m}}$ & $1.88571 \mathrm{E}-5 \mathrm{~m}^{2} / \mathrm{s}$ & Molecular diffusion coefficient \\
$q_{\mathrm{b}}$ & $6.6 \mathrm{E}-5 \mathrm{~m} / \mathrm{s}$ & Inland freshwater flux \\
$\rho_{0}$ & $1000 \mathrm{~kg} / \mathrm{m}^{3}$ & Freshwater density \\
$\rho_{\mathrm{s}}$ & $1025 \mathrm{~kg} / \mathrm{m}^{3}$ & Seawater density \\
$\epsilon$ & 0.025 & Density contrast parameter $\left(\rho_{\mathrm{s}}-\rho_{0}\right) / \rho_{0}$ \\
$\mu$ & $0.001 \mathrm{~kg} / \mathrm{ms}$ & Fluid viscosity \\
\hline
\end{tabular}

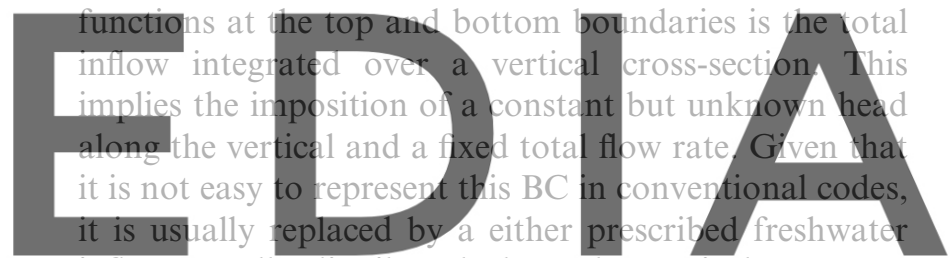

inflow equally distributed along the vertical or a prescribed head. Probably, neither option represents accu-

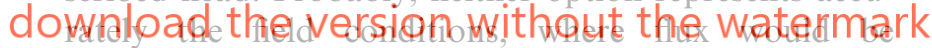
expected to be smaller and head larger at depth than near the surface. Yet, differences should be small.

- Seaside boundary condition.

Three different types of transport BC have been used to represent the contact with seawater. The first one, used by Henry [1], consists in specifying seawater concentration along the whole seaside boundary. It leads to unrealistic concentrations at shallow depths, where freshwater discharge should wash out saltwater. To overcome this problem a second $\mathrm{BC}$ was proposed by Huyakorn et al. [8], who divided the boundary into two parts prescribing freshwater concentration in the top part $(20 \%)$ to represent the discharge zone and prescribed seawater concentration in the rest. This BC prescribes the lower limit for outflowing freshwater with no a priori knowledge of where the change in the flow direction occurs. Unfortunately, the location of this point is very sensitive to changes in flow parameters and must be quantified anew whenever a parameter is modified. Furthermore, the validity of this $\mathrm{BC}$ is questionable, as in practice there is no sharp interface between freshwater and saltwater. The third and more realistic $\mathrm{BC}$ $[9,7]$ does not specify concentration but salt mass flux along the seaside boundary. Water entering the aquifer 
has saltwater concentration whereas the salt concentration of the outflowing water is that of the aquifer water. In any case, numerical calculations show that the choice of the $\mathrm{BC}$ has a moderate impact on the overall concentration distribution.

- Value of the diffusion coefficient (b dimensionless parameter).

Henry [1] expressed the transport equation in terms of fluid velocity. Porosity was not present in his equations. A number of authors [7,8] have considered the transport equation expressed in terms of Darcy's flux and, however, have used the same value of the diffusion coefficient as Henry. As a consequence, these authors used a smaller diffusion coefficient with the result that their simulations are not comparable.

- Stationarity of the simulations.

Henry's solution is steady state. However, most codes resolve the problem as the limit of a transient analysis. Actually, some authors choose to fix a time of $100 \mathrm{~min}$ in their numerical simulations. Given that the characteristic time of the problem exceeds 100 min [7], many of the less recent numerical simulations available in the literature do not reach steady state, and are therefore not comparable to the existing semi-analytical solutions.

\subsection{Limitations of the Henry problem}

The suitability of the Henry problem both as a paradigm for seawater intrusion and as a benchmark test for density dependent codes can be called into question. As regards the latter function, Simpson and Clement [12] found that the concentration distribution for the uncoupled problem (density variations disregarded within the aquifer but not at the boundaries) displays a pattern similar to that of the fully coupled problem because of the influence of the seaside boundary condition, which makes the problem somewhat irrelevant for benchmarking. However, one of the most seri-
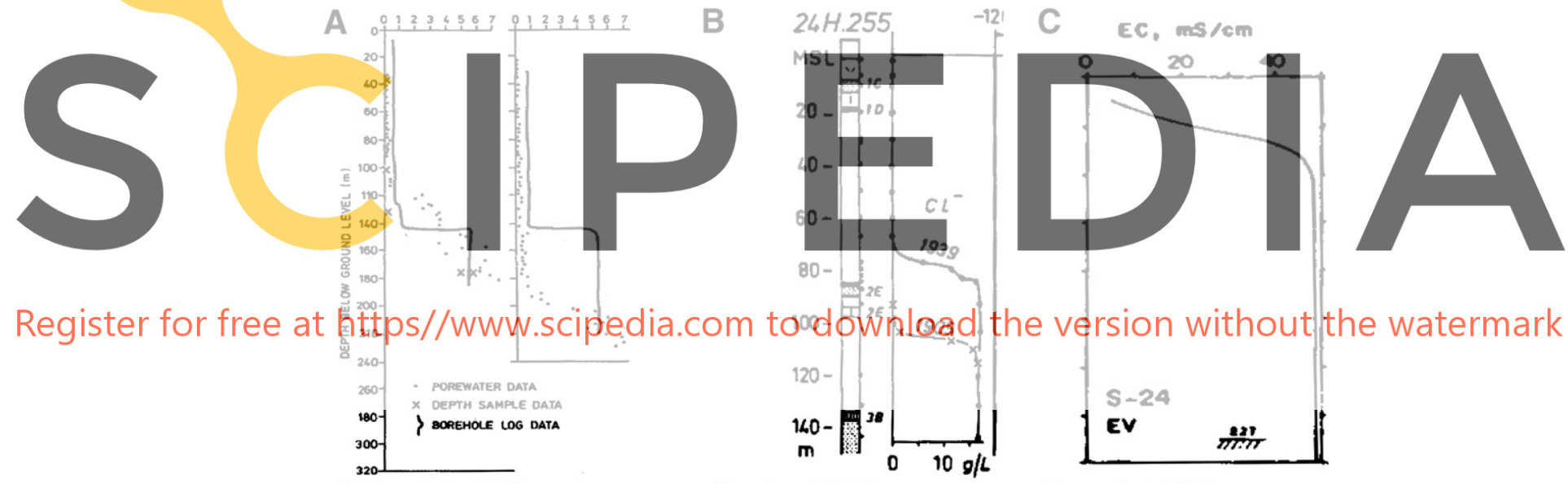

(Tellam et al., 1986)

(Stuyfzand, 1993)

(Baron et al., 1994)

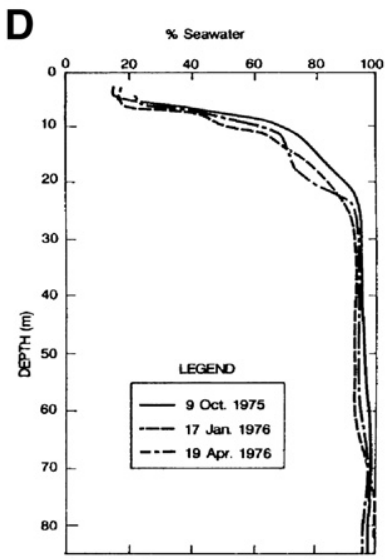

(Oberdorfer and Buddemeier, 1986)

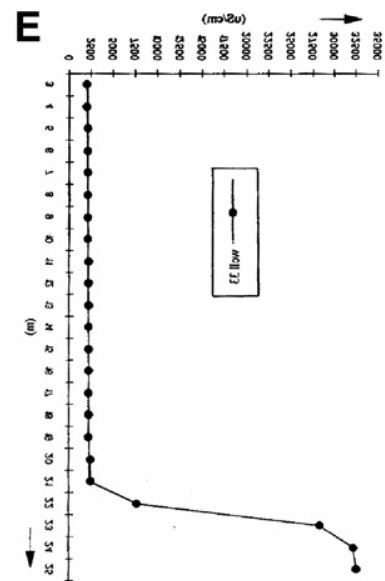

(Barbieri and Ghiglieri, 1994)
$\mathbf{F}$
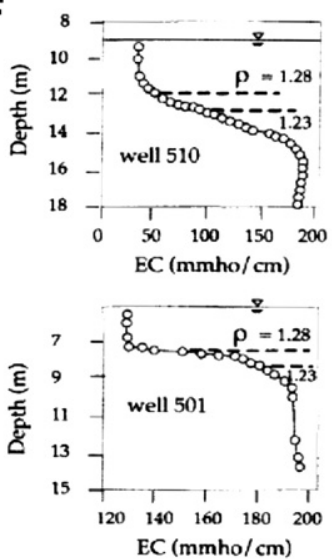

(Yechieli, 2000)

Fig. 2. Vertical electrical conductivity profiles and vertical salinity profiles in different aquifer formations: (A) Sandstone aquifers in the Lower Mersey Basin [16]; (B) western Netherlands [17]; (C) alluvial aquifer in the river Foxi Baxin, Sardinia, Italy [18]; (D) Enjebi Island, Enewetak coral atoll, Marshall Island, Pacific Ocean [19]; (E) carbonate aquifer in Mallorca Island, Spain [20]; (F) Dead sea area [21]. Note that Dead Sea density is about $1230 \mathrm{~kg} / \mathrm{m}^{3}$. Note that, while concentration is often constant below the mixing zone, its value is not always equal to that of seawater (cases A, B and C). 
ous drawbacks of the Henry problem is that computed concentration isolines do not resemble those observed in real coastal aquifers (Fig. 1). To illustrate this point, a review of measured salinity profiles published in seawater intrusion literature was carried out (Fig. 2). These profiles differ considerably from those arising from the Henry problem (Fig. 1). Salinity profiles are usually obtained by measuring the variation of electrical conductivity and temperature profiles with depth in open boreholes. It has been pointed out that these measurements are very sensitive to vertical flows that can disturb the salinity profile and produce step-like shape logs [13]. However, sharp fronts are observed even when pore water is sampled directly (Fig. 2a). Moreover, even if the shape of the profile is disturbed by the borehole, the fact remains that nearly $100 \%$ seawater salinity is often, though not always, observed at some depth, which cannot be explained by the Henry problem. Therefore, we believe that this is not a good representation of seawater intrusion. The value of the diffusion coefficient originally used by Henry is large (large value of the dimensionless parameter $b$ ) because the solution method would have failed to converge for values of $b$ closer to field values. It is therefore not suitable for simulating narrow mixing layers at the

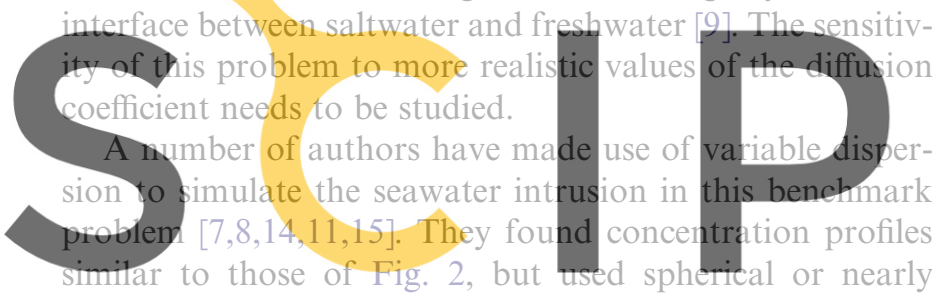
spherical dispersion tensors (longitudinal and transverse

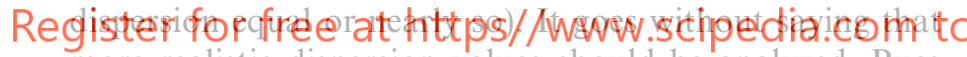
more realistic dispersion values should be analyzed. Bues and Oltean [11], who studied the advance of the diffusive and dispersive interface for $b=0.035$ and 0.1 , explicitly regretted the lack of analysis of the effect of different dispersion values.

Anisotropy is another characteristic of real aquifers which the Henry problem does not account for. Anisotropy in hydraulic conductivity may affect both seawater penetration and the flux of saltwater that enters the aquifer through the seaside boundary. The relevance of anisotropy has been often addressed in sharp interface approximation studies [22-26]. They found that the interface became less steep as this ratio increased. Also, calibration results of a density dependent flow model of the transition zone in a layered basalt aquifer in Oahu, Hawaii [27] showed that the best fitting models were those with an horizontal hydraulic conductivity that was significantly larger than the vertical one. Dispersion in anisotropic aquifers has also been considered by Reilly [28], who pointed out the need for a flow-direction-dependent dispersion formulation to study this effect.

The aim of this work is to present a more generic description of the seawater intrusion problem exemplified by the Henry problem that includes both velocity dependent dispersion and anisotropy in hydraulic conductivity.
A dimensionless analysis of the problem was carried out taking into account these parameters. A numerical analysis with the SUTRA code [29] was performed to assess the importance of the different dimensionless parameters in three very distinct quantities: (1) the interface penetration, (2) the width of the freshwater-saltwater transition zone, and (3) the amount of salt that flows into the system through the seaside boundary. The first two indicators are commonly used to describe the transition zone. The third indicator is useful for reactive transport processes in the mixing zone [30-32] as the reactions that take place are determined by the amount of saltwater that flows into the transition zone and mixes with freshwater. This latter variable has often been disregarded in seawater intrusion studies although it was recently analyzed by Smith [33].

\section{Methodology}

\subsection{Problem definition}

A vertical cross-section of a coastal aquifer is considered. Fluid flow is governed by Darcy's law (e.g., [34]), which reads in terms of the equivalent freshwater head $h$ as,

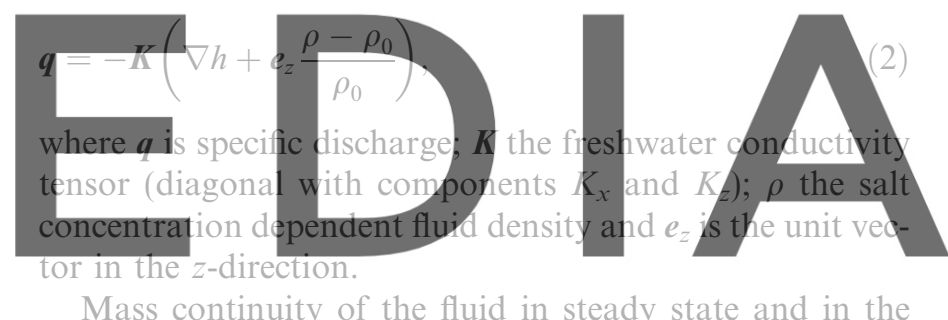

Mass continuity of the fluid in steady state and in the

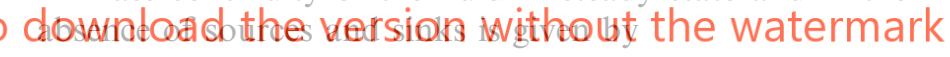
$\nabla \cdot\{\rho q\}=0$.

Fluid density depends on salt concentration $c, \rho=\rho(c)$ so that a constitutive equation is needed. Here we adopt a linear dependence of the fluid density on $c$,

$\rho=\rho_{0}\left(1+\epsilon \frac{c}{c_{\mathrm{s}}}\right)$,

where $\epsilon=\left(\rho_{\mathrm{s}}-\rho_{0}\right) / \rho_{0}$, and $c_{\mathrm{s}}$ is the salt concentration in seawater. Alternative approaches are suggested in the literature for cases where the contrast in densities is larger.

Eq. (3) is solved using Darcy's law (2) and the constitutive relationship (4), with the boundary conditions of specified flux $\left(q_{\mathrm{b}}\right)$ at the inland boundary $(x=0)$ and imposing $q_{z}=\left.0\right|_{z=0, d}$ at both the upper and bottom impermeable boundaries. At the seaside boundary, the seawater's equivalent freshwater head is specified:

$\left.h\right|_{x=L}=d+\epsilon(d-z)$.

Salt transport is described by the steady state advectiondispersion equation (e.g., [34]),

$\boldsymbol{q} \cdot \nabla c-\nabla\left(\boldsymbol{D}+\phi D_{\mathrm{m}} \boldsymbol{I}\right) \nabla c=0$,

where $\boldsymbol{I}$ is the identity matrix. The dispersion tensor $\boldsymbol{D}$ is defined by 
$D_{x x}=\alpha_{\mathrm{L}} \frac{q_{x}^{2}}{|q|}+\alpha_{\mathrm{T}} \frac{q_{z}^{2}}{|q|}$,

$D_{z z}=\alpha_{\mathrm{T}} \frac{q_{x}^{2}}{|q|}+\alpha_{\mathrm{L}} \frac{q_{z}^{2}}{|q|}$,

$D_{x z}=D_{z x}=\left(\alpha_{\mathrm{L}}-\alpha_{\mathrm{T}}\right) \frac{q_{x} q_{z}}{|q|}$

where $\alpha_{\mathrm{L}}$ and $\alpha_{\mathrm{T}}$ are the longitudinal and transverse dispersivity coefficients, respectively. Salt concentration $c$ is subject to the corresponding boundary conditions. Salt mass flux across the boundary is zero at the freshwater and horizontal boundaries.

At the sea boundary, we prescribe the salt mass flux according to

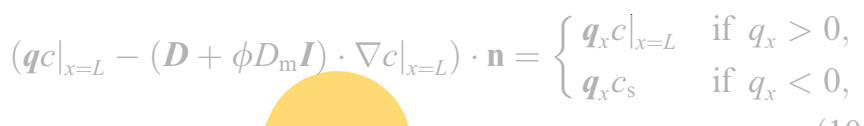

where $\mathbf{n}$ is normal to the boundary pointing outwards. Fluid enters the aquifer with seawater concentration but exits with aquifer's concentration.

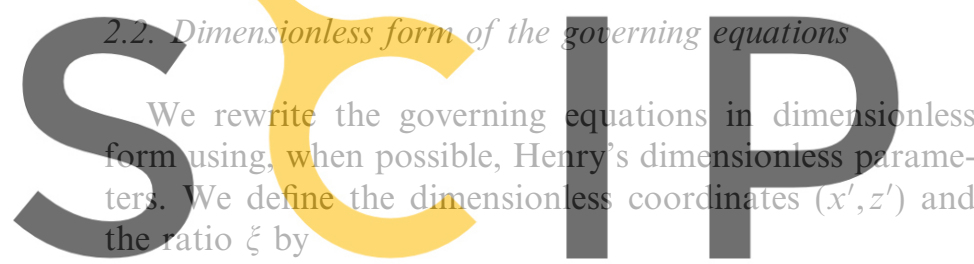

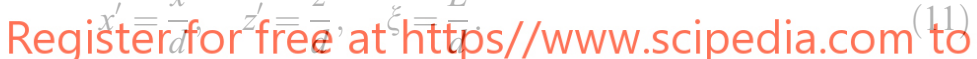

Darcy's velocity, freshwater head and salt concentration are written in dimensionless form as:

$\boldsymbol{q}^{\prime}=\frac{\boldsymbol{q}}{q_{\mathrm{b}}}, \quad h^{\prime}=\frac{h K_{x}}{q_{\mathrm{b}} d}, \quad c^{\prime}=\frac{c}{c_{\mathrm{s}}}$.

With these definitions, Darcy's law reads as

$q_{x}^{\prime}=-\frac{\partial h^{\prime}}{\partial x^{\prime}}, \quad q_{z}^{\prime}=-r_{K} \frac{\partial h^{\prime}}{\partial z^{\prime}}-\frac{1}{a} c^{\prime}$,

where

$a=\frac{q_{\mathrm{b}}}{\epsilon K_{z}}, \quad r_{K}=\frac{K_{z}}{K_{x}}$.

Here, $r_{K}$ denotes the hydraulic conductivity anisotropy ratio, and $a$ compares the freshwater influx, $q_{\mathrm{b}}$ to the characteristic buoyancy flux, $\epsilon K_{z}$. For isotropic hydraulic conductivity (i.e., $r_{K}=1$ ), $a$ is identical to the corresponding number defined by Henry [1]. Substituting (13) into (3) while using (11) and (12) leads to the dimensionless form of the flow equation:

$\frac{\partial^{2} h^{\prime}}{\partial x^{\prime 2}}+r_{K} \frac{\partial^{2} h^{\prime}}{\partial z^{\prime 2}}+\frac{1}{a} \frac{\partial c^{\prime}}{\partial z^{\prime}}=\frac{\boldsymbol{q}^{\prime} \epsilon \nabla^{\prime} c^{\prime}}{1+\epsilon c^{\prime}}$

where $\nabla^{\prime}$ indicates that the operator is written in the dimensionless coordinates.
The boundary conditions become:

$\left.\frac{\partial h^{\prime}}{\partial x^{\prime}}\right|_{x^{\prime}=0}=-1,\left.\quad h^{\prime}\right|_{x^{\prime}=\xi}=\frac{1}{a r_{K}}\left(1-z^{\prime}\right),\left.\quad q_{z}^{\prime}\right|_{z^{\prime}=0,1}=0$.

Similarly, the dimensionless form of the transport equation (6) becomes

$\boldsymbol{q}^{\prime} \cdot \nabla^{\prime} c^{\prime}-\nabla^{\prime}\left(\left(b_{\mathrm{L}} \boldsymbol{D}^{\prime}+b_{\mathrm{m}} \boldsymbol{I}\right) \nabla^{\prime} c^{\prime}\right)=0$

where dispersion is written in dimensionless form using Peclet numbers

$b_{\mathrm{m}}=\frac{\phi D_{\mathrm{m}}}{d q_{\mathrm{b}}}, \quad b_{\mathrm{L}}=\frac{\alpha_{\mathrm{L}}}{d}$

and the dimensionless dispersion coefficients,

$D_{x x}^{\prime}=\frac{q_{x}^{\prime 2}}{\left|q^{\prime}\right|}+r_{\alpha} \frac{q_{z}^{\prime 2}}{\left|q^{\prime}\right|}$

$D_{z z}^{\prime}=r_{\alpha} \frac{q_{x}^{\prime 2}}{\left|q^{\prime}\right|}+\frac{q_{z}^{\prime 2}}{\left|q^{\prime}\right|}$

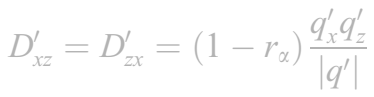

with

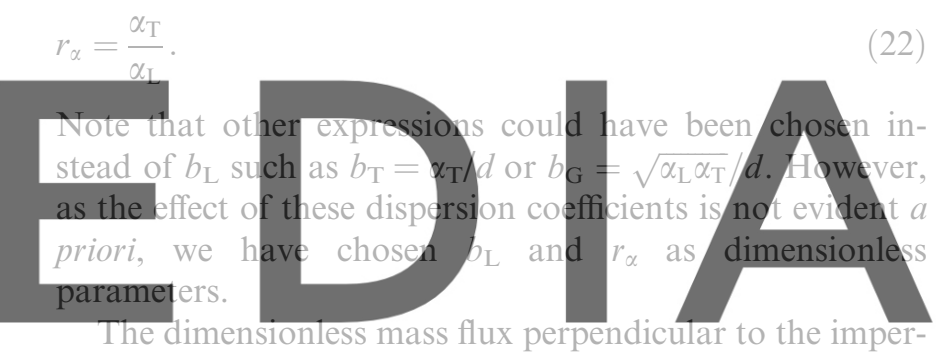

meable top and bottom and the freshwater boundaries is

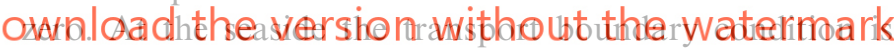
given by

$\left.\boldsymbol{q} c^{\prime}\right|_{x^{\prime}=\xi}-\left(\left.\left(b_{\mathrm{L}} \boldsymbol{D}^{\prime}+b_{\mathrm{m}} \boldsymbol{I}\right) \cdot \nabla^{\prime} c^{\prime}\right|_{x^{\prime}=\xi}\right) \cdot \mathbf{n}= \begin{cases}\left.q^{\prime} c^{\prime}\right|_{x^{\prime}=\xi} & \text { if } q_{x}^{\prime}>0, \\ \boldsymbol{q}^{\prime} & \text { if } q_{x}^{\prime}<0 .\end{cases}$

Thus, it turns out that the proposed problem can be written in terms equivalent to Henry's dimensionless parameters, $a$, $\xi$ and $b_{\mathrm{m}}$ and three additional numbers: $r_{K}$, which is needed to account for anisotropy in the hydraulic conductivity, and $b_{\mathrm{L}}$ and $r_{\alpha}$, which account for velocity dependent dispersion. Note that the flow Eq. (15) depends explicitly on $\epsilon$, which can be considered a model parameter (as it changes depending on the simulated salt and the reference concentration $c_{\mathrm{s}}$, for example). In such a case a different set of dimensionless variables could be considered. We prefer to use the dimensionless parameters as defined above to be consistent with the ones chosen by Henry [1]. In the context of seawater intrusion $\epsilon$ is small and the right side of (15) is of subleading order, which is reflected by the frequently employed Oberbeck-Boussinesq approximation. In fact, if this hypothesis was accepted, our results would apply to more saline water as long as density can be assumed to depend linearly on concentration. If $\epsilon$ is considered to be a model parameter, the above choice of dimensionless parameters is still valid in the sense that no additional 
dimensionless parameters are required. Nevertheless, $a$ and $c^{\prime}$ would need to be redefined as $a=q_{\mathrm{b}} / \epsilon_{\mathrm{R}} K_{z}$ and $c^{\prime}=\epsilon c /$ $\epsilon_{\mathrm{R}} c_{\mathrm{s}}$, where $\epsilon_{\mathrm{R}}$ is a reference coefficient depending on the type of salt. Since we will only consider seawater, we take $\epsilon_{\mathrm{R}}=\epsilon$ as that of seawater, and we do not vary this parameter in our analysis.

\subsection{Case definition}

In order to compare the diffusive and dispersive cases, a set of dimensionless parameters were chosen to describe the reference cases (Table 2). The longitudinal dispersivity coefficient used for the dispersive case was chosen so that $b_{\mathrm{L}}$ was equal to Henry's original $b_{\mathrm{m}}$ value. $k_{x}$ and $k_{z}$ were chosen so that their geometric mean equalled Henry's original conductivity value. Note that given that the permeability tensor is anisotropic and $a$ is defined in terms of $k_{z}$, its value is not exactly the one used by Henry in his original calculations. The $\xi$ factor used for these reference cases is 2 .

In addition to the two reference cases presented above, different sets of simulations were carried out varying each of the parameter values to assess their effect. Thus, $a$ was

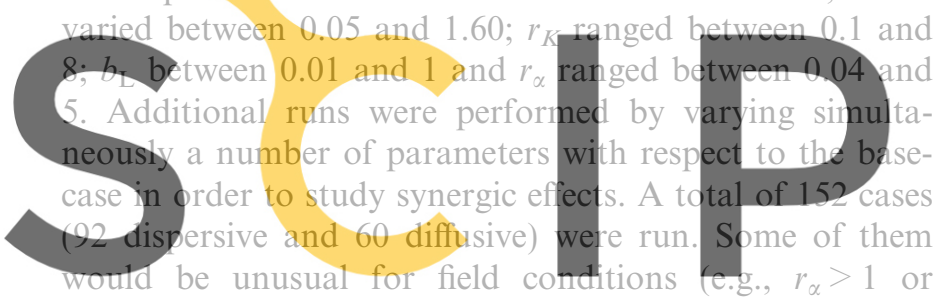
$\left.r_{K}<1\right)$. Yet, we ran them to explore the role of each

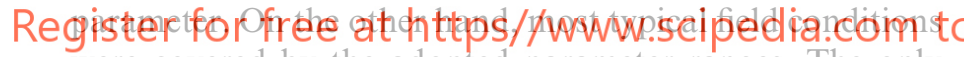
were covered by the adopted parameter ranges. The only exception was the permeability anisotropy (it is not unusual to find $\left.r_{K} \ll 0.01\right)$. Yet, smaller ratios led to extremely elongated intrusion wedges that might have produced numerical dispersion. Moreover, the smallest $r_{K}$ and $a$ values required the model domain to be elongated to avoid boundary effects. The resulting $\xi$ factors used in the simulations were 2, 4, 8 and 16 depending on the elongation needed. We assume that in reality $\xi$ is very large so that the values chosen for modelling would not affect the solution.

\subsection{Numerical analysis}

The proposed problem is studied in a numerical framework. The finite element code SUTRA [29] was used for the simulations. The grid used for all simulation with

Table 2

Dimensionless parameters for reference cases

\begin{tabular}{llllll}
\hline Case & $a$ & $r_{K}$ & $b_{\mathrm{m}}$ & $b_{\mathrm{L}}$ & $r_{\alpha}$ \\
\hline Diffusive & 0.3214 & 0.66 & 0.1 & 0 & 0 \\
Dispersive & 0.3214 & 0.66 & 0 & 0.1 & 0.1 \\
\hline
\end{tabular}

$\xi=2$ was regular with $256 \times 128$ elements. The stability of the solution with the grid spacing was tested with grids of $200 \times 100$ and $400 \times 200$ elements, obtaining the same result in all cases. However, the $256 \times 128$ grid was chosen to be on the safe side when modifying parameters to perform the sensitivity analysis. Other studies performed with this shape factor [35] showed that the results of different numerical diffusive solutions displayed no significant discrepancies for grid Peclet numbers below 1. Benson et al. [15] studied numerical dispersion in this type of problem (diffusive and dispersive form) using SUTRA and demonstrated that the solution was stable for grid spacing snot exceeding $4 \mathrm{~cm}$. The grid was modified with increasing $\xi$. A grid of $512 \times 128$ elements was used to simulate the cases with $\xi=4$ and 8 whereas a grid of $768 \times 128$ was employed for the cases with the aspect ratio of 16 .

\subsection{Variables of interest}

Seawater intrusion studies are usually concerned with the depth of inland penetration of saltwater as this characterizes the size of the contaminated zone. Therefore,

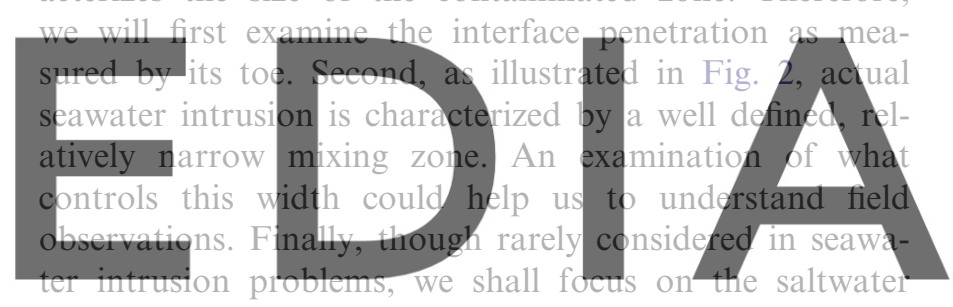

flux which plays an important role in controlling geo-

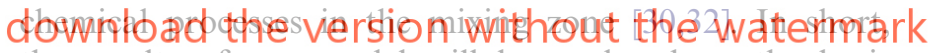
the results of our model will be analyzed on the basis of the following parameters:

- $L_{\mathrm{D}}=L_{\mathrm{toe}} / d$ (Dimensionless toe penetration) $L_{\mathrm{toe}}$ is the penetration of the seawater intrusion wedge measured as the distance between the seaside boundary and the point where the $50 \%$ mixing isoline intersects the aquifer bottom (see Fig. 3)

- $W_{\mathrm{D}}$ (Dimensionless averaged width of the mixing zone) is computed by averaging $\mathrm{WMZ} / d$, where $\mathrm{WMZ}$ is the vertical distance between isoconcentration lines of $25 \%$ and $75 \%$ mixing ratios. In order to overcome boundary effects, averaging was restricted to the interval between $0.2 L_{\mathrm{D}}$ and $0.8 L_{\mathrm{D}}$ (see Fig. 3). Width was also measured along the concentration gradient, i.e., perpendicular to the interface. However, since the values obtained in both ways displayed a linear relationship, the first method was preferred given that it offers a better representation of what is actually measured in the field.

- $R_{\mathrm{D}}=q_{\mathrm{s}} / q_{\mathrm{b}}$ (Dimensionless saltwater flux) where $q_{\mathrm{s}}$ is the saltwater flux that enters the system through the seaside boundary $\left(\mathrm{m}^{3} / \mathrm{s} / \mathrm{m}\right)$, evaluated using (23) integrated over the inflowing part of the domain. Therefore, $R_{\mathrm{D}}$ is the ratio between the volumetric flow rates of inflowing seawater and freshwater. 


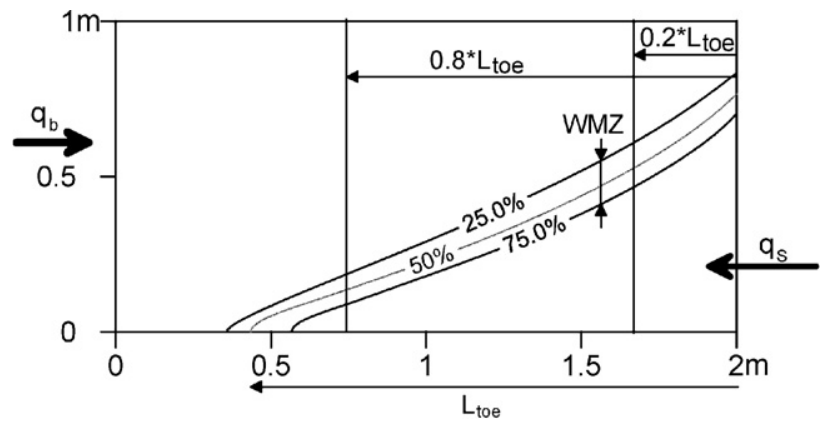

Fig. 3. Schematic description of the variables used to quantify seawater intrusion: Toe penetration $\left(L_{\mathrm{toe}}\right)$, width of the mixing zone (WMF) and incoming saltwater flux $\left(q_{\mathrm{s}}\right)$.

\section{Results}

\subsection{Diffusive versus dispersive Henry problem}

Results for the diffusive and dispersive reference cases (Table 2) are shown in Fig. 4. While the diffusive solution displays the typical broad mixing zone of the Henry problem, the dispersive solution displays the nearly pure seawa-

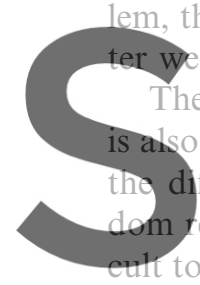

The difference between the diffusive and dispers ve cases

strated by the vertic

eaches values near seawater

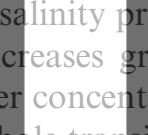

files (Fig. 5). In

tion. It is diffi-

on zone can be

observed (in our plot this only happens in section C at a

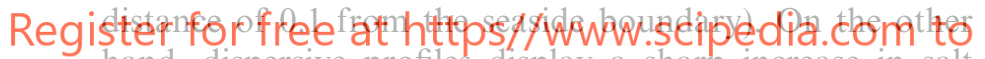
hand, dispersive profiles display a sharp increase in salt content, resulting in a thinner transition zone and reaching values closer to seawater concentration even in sections that are located at some distance from the sea shore. Dispersive profiles resemble to those presented in Fig. 2.

The use of velocity dependent dispersion improves the realism of the solution. However, a sensitivity analysis to the Peclet numbers (Fig. 6) reflects that the poor behavior of Henry's original problem is not caused by the diffusive (i.e., velocity independent) nature of mixing. A reduction of the diffusion coefficient leads to concentration profiles similar to those observed in reality and obtained with dispersive mixing. This could have been overlooked because the influence of Henry's solution was so strong that few authors [11] studied its sensitivity to $D_{\mathrm{m}}$. In fact, both the diffusive and dispersive problems tend to the GhybenHerzberg (static seawater, sharp front) solution as $b$ tends to 0 with the result that they should be identical in the limit.

The solution of the Henry problem is strongly influenced by the seaside boundary condition. This effect is so compelling that neither equivalent freshwater heads nor concentrations are dramatically changed if density dependence is ignored within the domain [12]. The dispersive problem displays obvious differences for the flow solution as well as for the concentration distribution for the uncoupled and fully coupled dispersive Henry problems (Fig. 7). Thereby, the dispersive problem does not present this disadvantage. However, a similar result is obtained for a diffusive problem with the $b_{\mathrm{m}}$ parameter reduced by a factor of 10 (Fig. 8). Comparing this result to the coupled solution for the diffusive problem with $b_{\mathrm{m}}=0.01$ in Fig. 6, the differences between the uncoupled and coupled solution for the reduced diffusion problem are evident. Therefore, the solutions of the resulting diffusive problem with reduced diffusion or the dispersive problem are suited to benchmarking because the solution is sensitive to density depen-

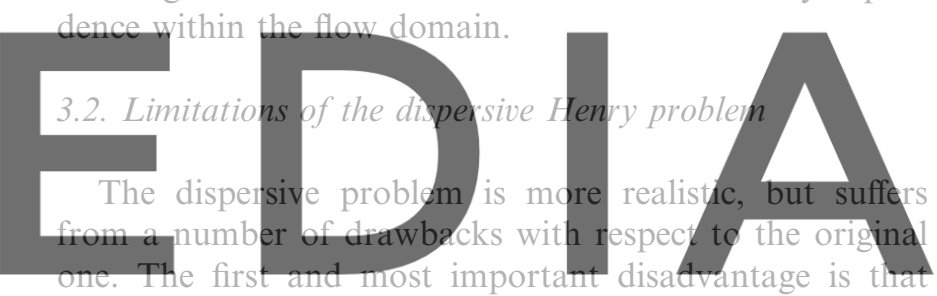

there is no analytical solution with which to compare dowarlesatd. thiey version which undermines the main advantage of the Henry Problem as a benchmark test. The second drawback is that numerical complexity is increased. Longer transient simulations are needed to reach steady state [11]. The time needed depends on the values of the dimensionless parameters chosen. For the reference dispersive case described in Table 2, about $1000 \mathrm{~min}$ are needed. This time corresponds to the time in which the $10 \%$ mixing line reaches the equilibrium. The $50 \%$ line is suitable for evaluating the penetration of the saltwater wedge but not for analyzing the width of the mixing zone since the fresher side of the mixing zone takes longer than the $50 \%$ isoline to reach steady state.
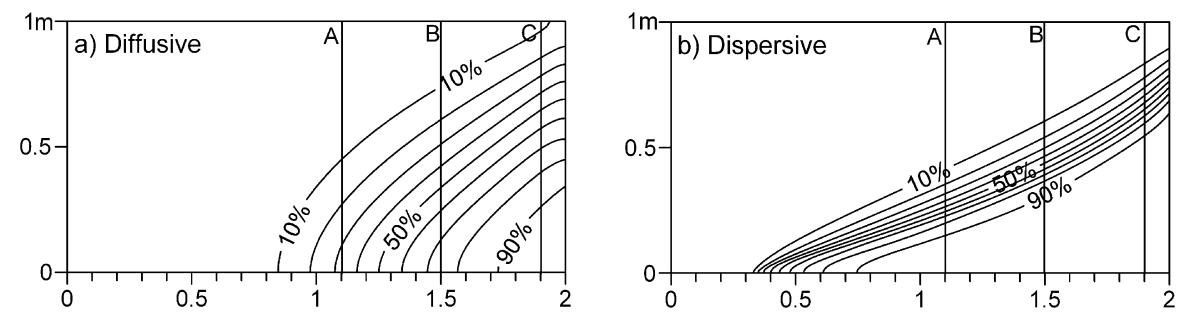

Fig. 4. Diffusive seawater-freshwater mixing zone (a) compared with a purely dispersive mixing zone (b) for the reference cases (dimensionless parameters of Table 2). Note that, in contrast to the diffusive case, the purely dispersive problem displays a well defined wedge with a concentration close to seawater at depth. 

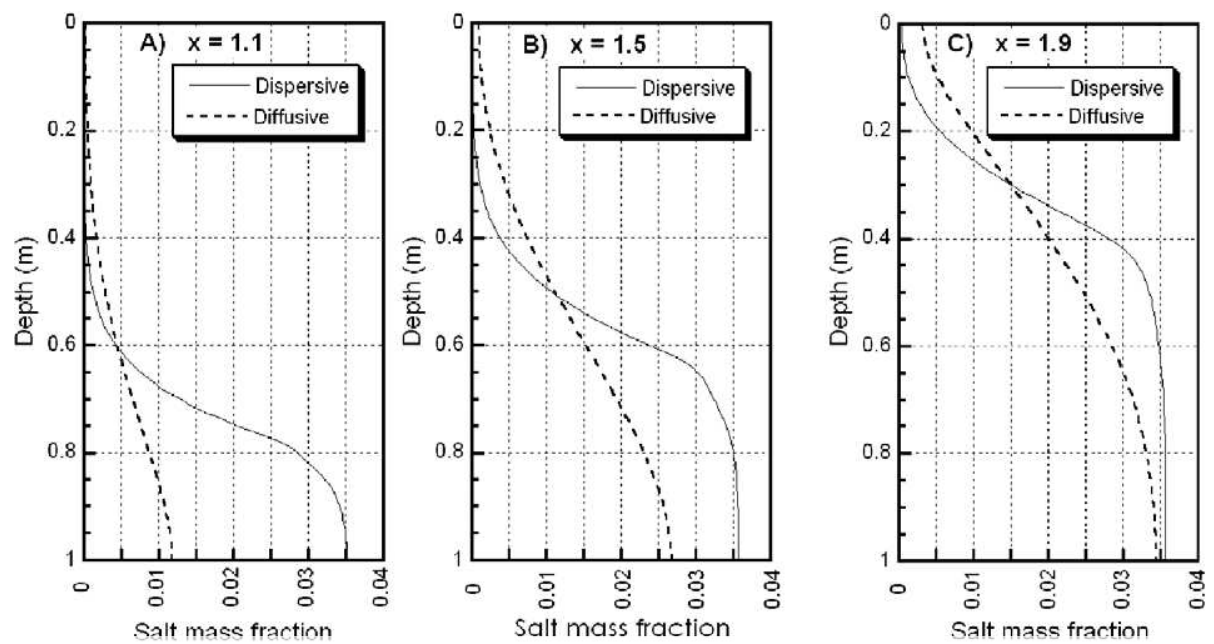

Fig. 5. Diffusive and dispersive vertical salinity profiles located in the position indicated in Fig. 4 at $x=1.1$ (A), 1.5 (B) and 1.9 (C)

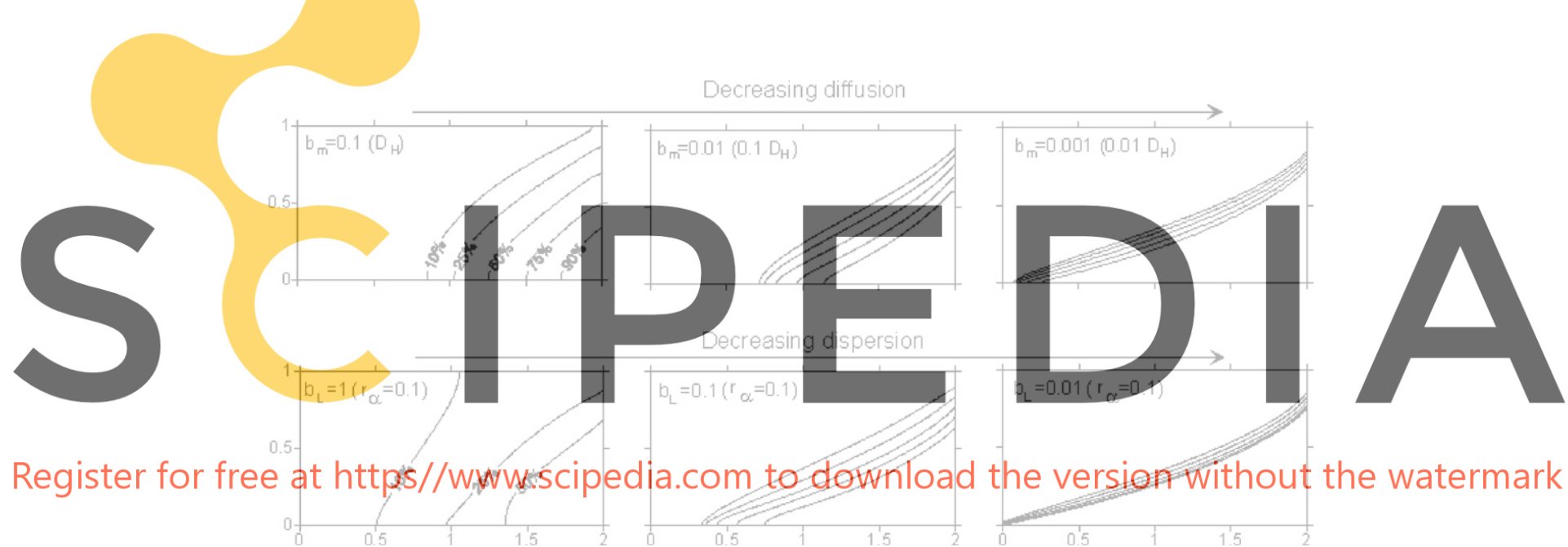

Fig. 6. Change in the interface shape and location with increasing diffusion (upper row) and increasing dispersion (lower row).
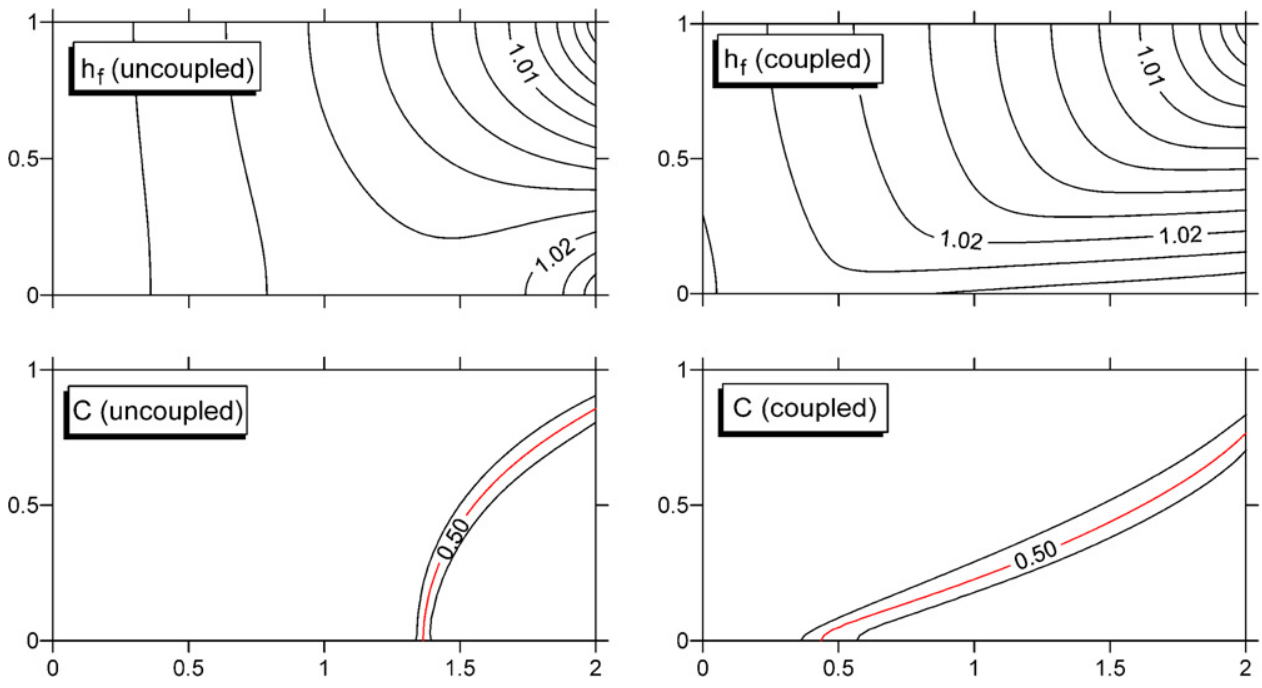

Fig. 7. Equivalent freshwater heads $\left(h_{\mathrm{f}}\right)$ and concentration distributions $(\mathrm{C})$ for the uncoupled (i.e., ignoring density variability within the domain) and coupled (i.e., acknowledging concentration dependence of density) dispersive Henry problem. 


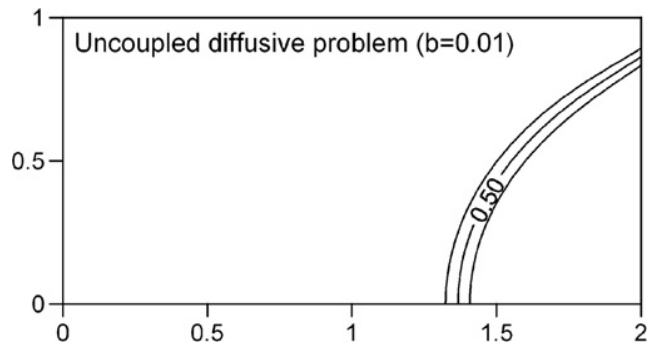

Fig. 8. Concentration distribution for the uncoupled diffusive Henry problem with reduced diffusion coefficient $\left(b_{\mathrm{m}}=0.01\right)$. Equivalent freshwater heads are the same as in Fig. 7 for the uncoupled problem.

The anisotropic dispersive problem is closer to reality than the original problem although it is still removed from reality. It does not account for relevant factors such as: tidal effects, three-dimensionality, heterogeneity, transient variations of the freshwater recharge, unsaturated effects, etc. It should be viewed as a first step towards understanding the basics of the velocity dependent dispersion affecting seawater intrusion. Efforts are currently being devoted to study the effect of the combination of these factors in the evolution of seawater intrusion. These factors should be

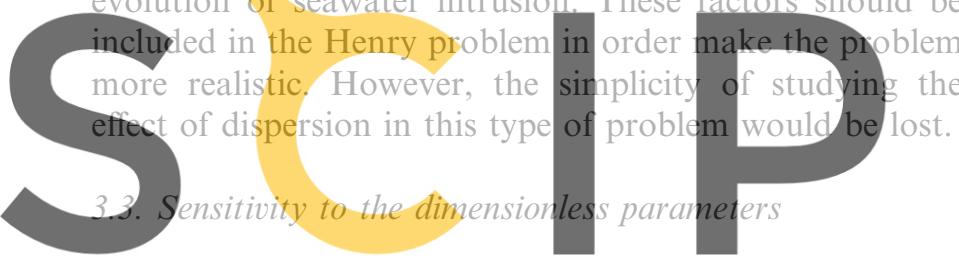

The shape and penetration of the saltwater intrusion

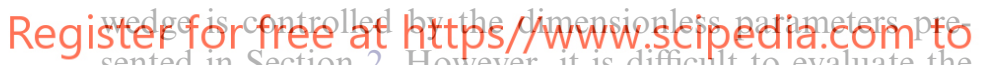
sented in Section 2. However, it is difficult to evaluate the relative importance of these parameters. Here, we examine the results obtained when varying the parameters with respect to the base-case, as discussed in Section 2. In order to identify the parameter (or combination of parameters) that controls each output variable, we employed the IMSL routine DRBEST [37], which selects the best multiple linear regression model using the algorithm of Furnival and Wilson (1974) to identify the parameters that best explain the model output. The resulting regression models for each output variable ( $L_{\mathrm{D}}, W_{\mathrm{D}}$ and $R_{\mathrm{D}}$ ) for the diffusive and dispersive cases are presented below. These results are valid for the model geometry and boundary conditions of the Henry problem.

\subsubsection{Toe penetration $\left(L_{D}\right)$}

In order to describe the toe behavior, we must first recall the Ghyben-Herzberg $(\mathrm{GH})$ approximation which consists of neglecting mixing and, hence, salt fluxes. The toe position derived from this assumption can be expressed in terms of the dimensionless parameters defined in Section 2:

$$
L_{\mathrm{GH}_{\mathrm{D}}}=\frac{L_{\mathrm{GH}}}{d}=\frac{1}{2 a r_{K}}
$$

This expression is the limit case when diffusion $\left(b_{\mathrm{m}}\right)$ or dispersion $\left(b_{\mathrm{L}}\right)$ tend to 0 . The toe recedes when diffusion/dispersion is increased. The deviation from $L_{\mathrm{GH}}$ is due to the head loss caused by seawater flux. Since this is driven by

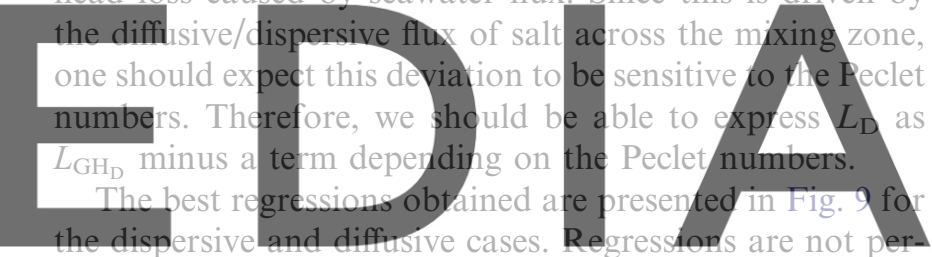

fect, especially for the dispersive case. The existence of

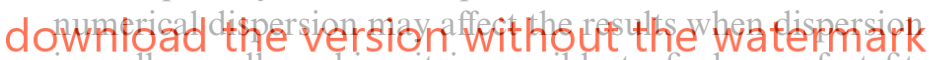
is really small, making it impossible to find a perfect fit. Nevertheless, the regressions allows us to identify the key factors affecting the toe position. It should be noted that in both problems the deviation from the Ghyben-Herzberg toe position is a function of the Peclet number:
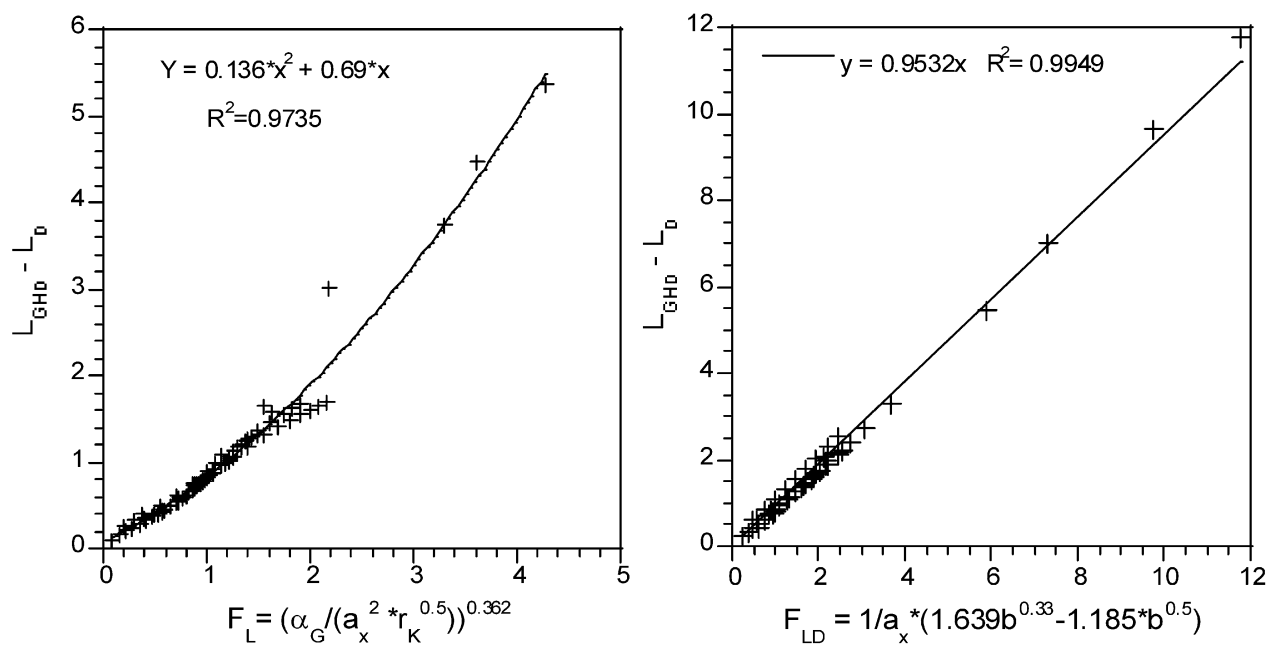

Fig. 9. Regressions obtained for the deviation of the toe penetration with respect to the Ghyben-Herzberg toe position for the dispersive (left) and diffusive (right) case. 
$F_{\mathrm{LDS}}=0.136\left(\frac{\alpha_{\mathrm{G}}}{a_{x}^{2} \sqrt{r_{K}}}\right)^{0.724}+0.69\left(\frac{\alpha_{\mathrm{G}}}{a_{x}^{2} \sqrt{r_{K}}}\right)^{0.362}$

for the dispersive problem

$F_{\mathrm{LDF}} \simeq \frac{1.64 b^{\frac{1}{3}}-1.18 b^{\frac{1}{2}}}{a_{x}}$ for the diffusive problem

where $a_{x}=a r_{K}=q_{\mathrm{b}} / K_{x} \epsilon$ and $\alpha_{\mathrm{G}}=\sqrt{\alpha_{\mathrm{L}} \alpha_{\mathrm{T}}}$.

The points that diverge from the regressions are those whose anisotropy ratio $\left(r_{K}\right)$ is smaller than 0.5 . This indicates that the effect of a strong anisotropy is not properly characterized by these expressions. This may be a result of ignoring anisotropy in the permeability when evaluating $L_{\mathrm{GH}_{\mathrm{D}}}$.

\subsubsection{Width of the mixing zone $\left(W_{D}\right)$}

The average width of the mixing zone was evaluated only for the dispersive case. As shown in Fig. 5, the width of the mixing zone is highly dependent on $x$ for the diffusive case, owing to the high diffusion coefficient used in most diffusive simulations. Moreover, it is truncated by the upper and lower boundaries. Therefore, we do not consider it to be a representative parameter for the diffusive problem.
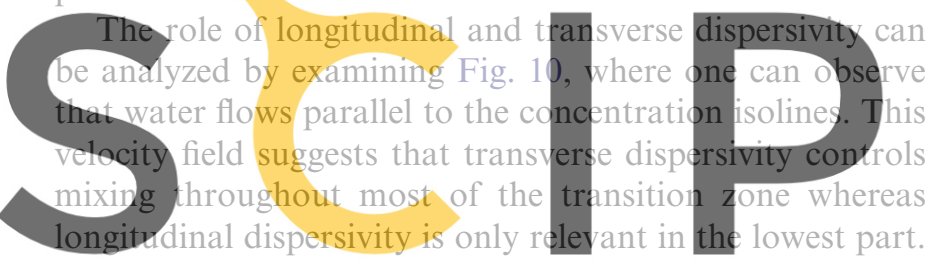

A close analysis of Fig. 10 yields some insights into transport processes in the mixing zone. Above the $60 \%$ isoline

Register fortree athintps.

is carried into the freshwater region by lateral dispersion. Upwards increase in the separation leads to both a decrease in the dispersive flux (some salt is transported along the mixing zone because water flux also increases seawards) and to an increase in the dispersion (in response to the increase in flux). Below the $60 \%$ isoline, the water flux is small so that both longitudinal dispersion and advection also contribute to the upwards salt flux. Overall, salt is dispersed upwards and advected sideways. The water flux and dispersion increase seawards as does the returning salt flux, thus balancing the essentially advective but continuous flux below the mixing zone.

The foregoing account shows that the interplay between advection and longitudinal and transverse dispersion is not trivial even in this idealized problem. Based on stochastic transport results, most authors argue that transverse dispersion would tend to zero for long travel distances [38]. Yet, other authors maintain that the interplay between spatial heterogeneity and time fluctuations of velocity leads to sizeable macroscopic large scale transverse dispersion [3941]. The fact that the behavior of the mixing zone is so sensitive to transverse dispersion implies that actual detailed measurements in the mixing zone would help us to better understand field scale lateral dispersion.

The multi-regression analysis revealed a linear relationship between the width of the mixing zone, $W_{\mathrm{D}}$, and the geometric mean of the two dispersivities (Fig. 11). The resulting expression to determine the vertical width of the mixing zone is
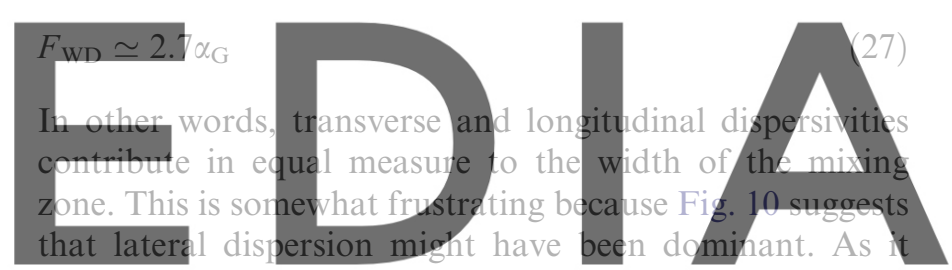

turns out, the areas where the salinity gradient is not parallel to the water flux (near the toe and the saltwater side downlpad the yersign without the matermark width of the mixing zone as the rest.

Some simulations were carried out to identify the individual role of the longitudinal and transverse dispersivities (Fig. 12). The most extreme cases are not realistic but have been included to enhance the individual effect of these parameters. Fig. 12 shows that an increase in the longitudi-

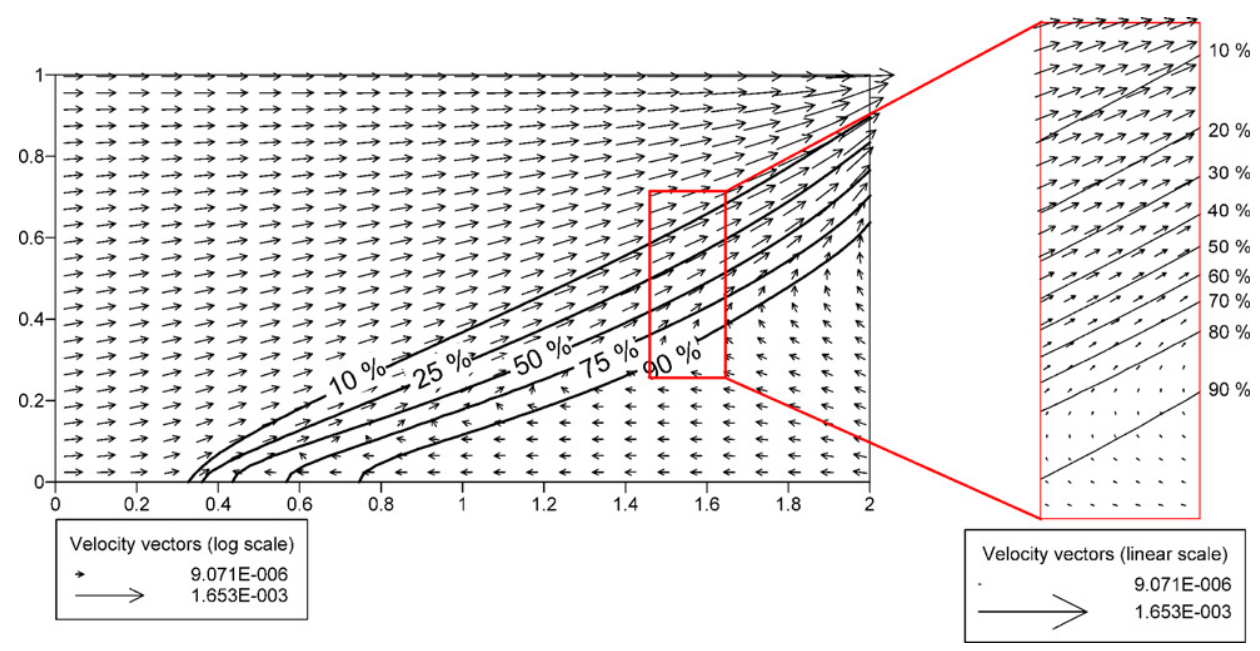

Fig. 10. Velocity field and 25, 50 and $75 \%$ concentration isolines in the dispersive reference case. 


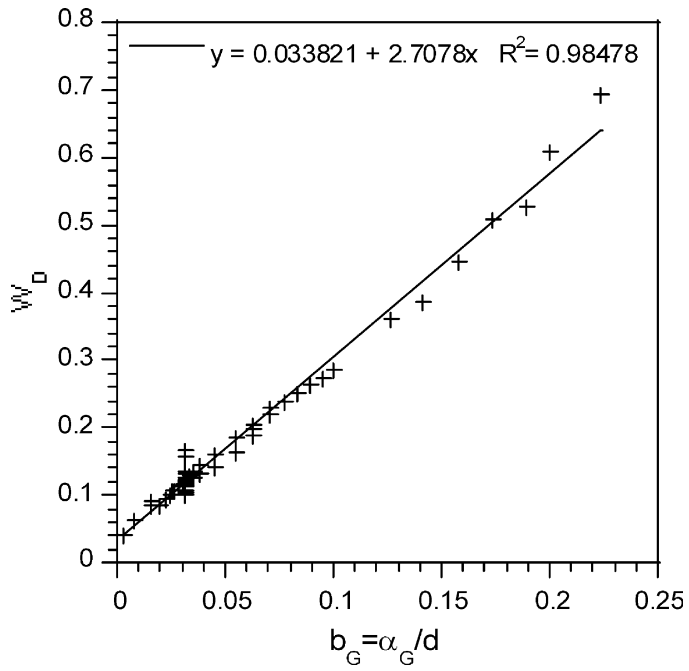

Fig. 11. Linear relationship of the width of the mixing zone with respect to the geometric mean of the dispersivity coefficients.

nal dispersivity widens the lower part of the mixing zone where the concentration gradient and the velocity vector are parallel. Note that the line of $10 \%$ of seawater concentration remains static whereas the mixing zone broadens downwards and seawards. The freshwater area is not affected, $\alpha_{\mathrm{L}}$ just affects the concentration distribution inside the saltwater wedge. This distribution is consistent with vertical salinity logs (Fig. 2A, B and C). These logs usually display a sharp jump in salinity, but salinity underneath the jump often remains well below seawater concentration. This indicates that, at least in these cases, transverse dispersivity may be much smaller than the $0.1 \alpha_{\mathrm{L}}$ value, which is often used in practice and adopted here for the base-case.

The effect of increasing transverse dispersivity widens the mixing zone in general. It has a shear effect, pushing the mixing zone backwards at the bottom and inland at the top. As a result, the slope of the isoconcentration lines increases. It should be pointed out that the discharge part in the seaside boundary becomes wider as the transverse dispersivity increases.

\subsubsection{Dimensionless saltwater flux $\left(R_{D}\right)$}

The saltwater flux is expected to depend on hydraulic conductivity, freshwater inflow (i.e., the $a$ parameter) and on the diffusion/dispersion coefficients (i.e., the Peclet numbers). In fact, if there was no mixing, there would be no saltwater flux. Nevertheless, the question of whether it is the transversal or the longitudinal dispersivity that controls the saltwater flux remains unresolved. Transverse dispersion is expected to play a more influential role, since most of the mixing occurs orthogonally to the water flux along the mixing zone. Smith [33] has addressed the importance of the quantification of the saltwater flux in seawater intrusion studies with velocity dependent dispersion. Although he used another conceptual model and different seaside boundary conditions, his results are relevant to our study. He found an expression to assess the ratio between saltwater and freshwater inflow for isotropic and anisotropic cases. The expression for the isotropic case fitted his results accurately as well as some results from the literature. His expression for the anisotropic case was not as good, but satisfactory. He found that saltwater flux depends on the geometric average of the hydraulic conductivity, $K_{\mathrm{G}}$, and on the square root of $\alpha_{\mathrm{T}}$.

We found that the simplest combinations of model parameters that account for a large percentage of the variability on $R_{\mathrm{D}}$ are $b_{\mathrm{T}}^{\frac{1}{3}} / a_{\mathrm{G}}$ for the dispersive case and $b^{\frac{1}{4}} / a_{\mathrm{G}}$ for the diffusive problem, where $b_{\mathrm{T}}=\alpha_{\mathrm{T}} / d$ is the lateral dispersion Peclet number and $a_{\mathrm{G}}=q_{\mathrm{b}} / \epsilon K_{\mathrm{G}}$ with $K_{\mathrm{G}}=\sqrt{K_{x} K_{y}}$. The resulting relationships between are shown in Fig. 13. Note that the relationship is nearly linear for $b_{\mathrm{T}}^{\frac{1}{3}} / a_{\mathrm{G}}<2$ and $b^{\frac{1}{4}} / a_{\mathrm{G}}<4$. In such case, the volumetric salt flux becomes

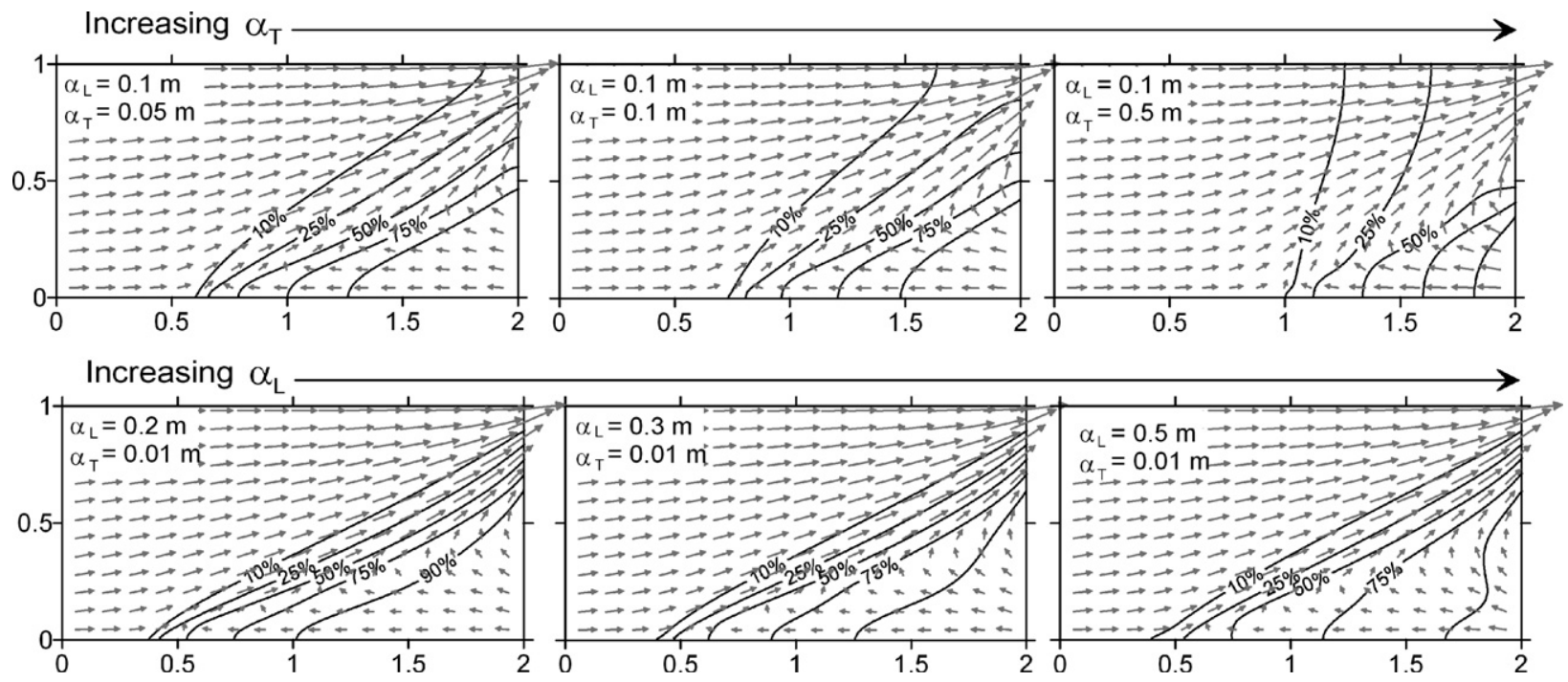

Fig. 12. Concentration distribution for different simulations showing the effect of increasing individually the longitudinal and the transversal dispersion coefficient. 
$q_{\mathrm{s}}=q_{\mathrm{b}} R_{\mathrm{D}} \simeq 0.26 \epsilon\left(\frac{\alpha_{\mathrm{T}}}{d}\right)^{\frac{1}{3}} K_{\mathrm{G}}$,

$q_{\mathrm{s}}=q_{\mathrm{b}} R_{\mathrm{D}} \simeq 0.16 \epsilon\left(\frac{D_{\mathrm{m}}}{q_{\mathrm{b}} d}\right)^{\frac{1}{4}} K_{\mathrm{G}}$

i.e., seawater flux is essentially proportional to $K_{\mathrm{G}}$ and $\alpha_{\mathrm{T}}^{\frac{1}{3}}$ (and independent of $q_{\mathrm{b}}$ for the dispersive problem!).

\section{Discussion and conclusions}

The Henry problem has played a significant role in our understanding of seawater intrusion, but displays severe limitations both as a paradigm and as a benchmark test for density dependent flow codes. We believe that these drawbacks do not arise from the problem itself but from the values of the dimensionless numbers that Henry used to solve the problem semi-analytically and that have been used by most researchers ever since. Simpson and Clement [36] proposed a reduction of the value of the $a$ parameter (dimensionless freshwater flux). Here we propose reducing the $b$ parameter (Peclet number). The resulting problem is sensitive to density variations within the domain and thus more suitable for testing seawater intrusion codes where stable density profiles extend throughout most of the domain. A second feature of the reduced diffusion problem is a seawater intrusion wedge that is consistent with widely accepted concepts and concentration profiles are similar to those observed in the field.

However, we propose the use of an alternative that accounts for velocity dependent dispersion and anisotropic hydraulic conductivity. This dispersive Henry problem is a valuable tool for gaining some insight into the mechanisms controlling seawater intrusion into coastal aquifers. As with the diffusive Henry problem, the dispersive version produces a wedge where seawater flows horizontally towards an inclined mixing zone. In this zone, salt is dispersed into the outflowing freshwater and floats upwards due to the reduction in its density. As it mixes with fresh- water essentially by transverse dispersion, it is carried back to sea, giving rise to a saltwater circulation cell.

We discuss the behavior of the solution in terms of three output variables: toe penetration, width of the mixing zone and saltwater flux (Fig. 14). To this end, we first performed a dimensional analysis to identify the governing parameters and chose as dimensionless parameters those of the original Henry problem: $a$, dimensionless freshwater flux (relating viscous and buoyancy forces) and $b$, Peclet number, denoted by $b_{\mathrm{L}}$ when diffusive mixing is replaced by dispersive mixing. Two new dimensionless parameters emerge: $r_{\alpha}$ and $r_{K}$, anisotropy ratios for dispersivity and hydraulic conductivity, respectively.

Toe penetration $L_{\mathrm{D}}$ is described qualitatively by the Ghyben-Herzberg approximation (e.g., [34]). $L_{\mathrm{D}}$ decreases with the dimensionless freshwater flux $a$. As seawater flux causes a seawater head loss, the saltwater wedge recedes with increasing dispersion (i.e., $L_{\mathrm{D}}$ decreases). Deviations with respect to $L_{\mathrm{GH}}$ depend on the geometric average of dispersivities.

The width for the dispersive case is quite constant along the mixing zone and is controlled basically by $\alpha_{\mathrm{G}}=\sqrt{\alpha_{\mathrm{L}} \alpha_{\mathrm{T}}}$. While the contribution of the two dispersivities is quantitatively similar, they affect the concentration profile in different ways. Transverse dispersivity contributes to the broadening of the concentration profile throughout the domain. Increasing longitudinal dispersivity, on the other hand, leads to seawards displacement of the high concentration isolines, leaving the freshwater end unaffected. As a result, vertical concentration profiles still display a marked concentration increase in the mixing zone but leading to concentrations well below seawater $(75-90 \%)$. Since this feature is often observed in actual salinity logs, we infer that longitudinal dispersivity may exceed transverse dispersivity by much more than the traditional factor of 10 . High sensitivity of width to dispersivities is especially relevant because these parameters are usually hard to characterize, while the width of the mixing zone can be measured. This
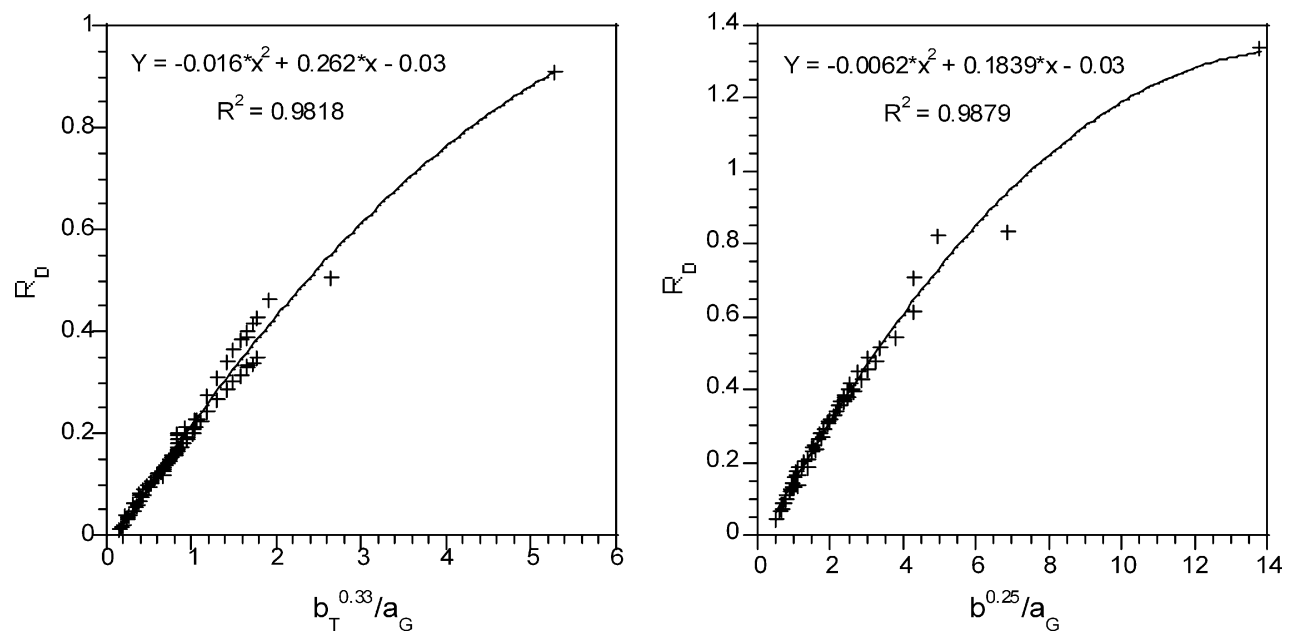

Fig. 13. Regressions obtained for the dimensionless saltwater flux for the dispersive (left) and diffusive (right) cases. 

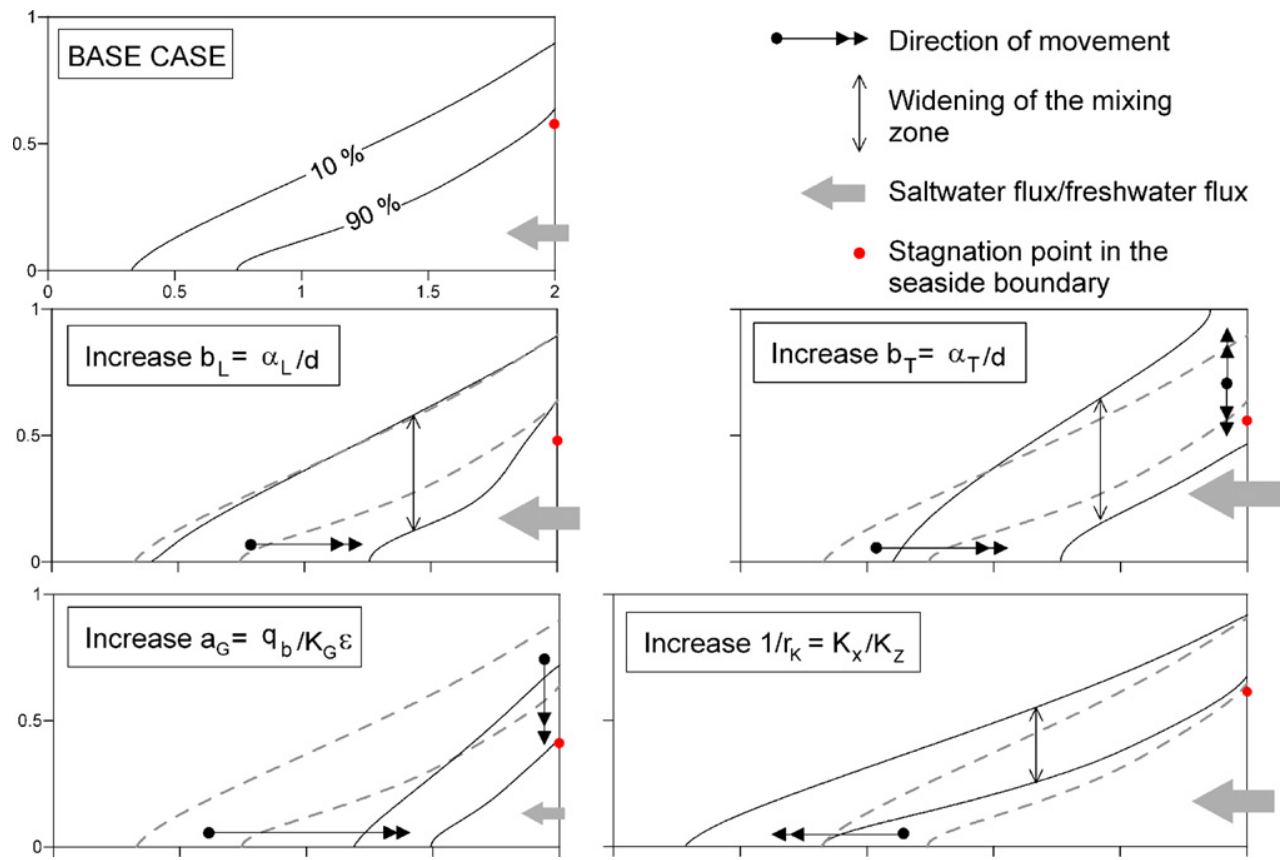

Fig. 14. Qualitative behavior of the solution to the dispersive Henry problem. As longitudinal dispersivity increases so do seawater flux and the width of the mixing zone, whose saline end moves seawards. Increasing transverse dispersivity broadens and tilts the mixing zone, while also increasing seawater flux. Increasing the dimensionless freshwater flux pushes the mixing zone seawards whereas an increase in the ratio $k_{x} / k_{z}$ pushes it landwards.

finding implies that the width can be used to derive field values of dispersivity.

Saltwater flux through the seaside boundary is basically proportional to $K_{\mathrm{G}}$ (geometric average of the principal hydraulic conductivities) times the cubic root of the transverse dispersivity. These parameters are similar to these obtained by Smith [33]. Saltwater flux is usually considered small when compared with the freshwater flux. The extreme case is the sharp interface approximation that neglects saltwater circulation. However, saltwater fluxes computed here are of the order of 10 to $90 \%$ of the freshwater flux. An accurate quantification of the saltwater flux is important for reactive transport processes in the mixing zone and should merit special attention in seawater intrusion studies.

Results show that the some of the key factors controlling the studied variables are not explicitly present in the dimensional analysis of Section 2.2. The geometric means of hydraulic conductivity and dispersivity coefficients should appear in the dimensionless numbers, $a_{\mathrm{G}}$ being a better expression for the relationship between viscous and buoyancy forces and $b_{\mathrm{G}}$ or $b_{\mathrm{L}}$ being better expressions of the Peclet number. The effect of these factors is summarized in Fig. 14.

\section{Acknowledgements}

This work was funded by the European Commission (SALTRANS project, contract EVK1-CT-2000-00062). The first author was supported by the Autonomous government of Catalonia with a FI doctoral scholarship and by the Technical University of Catalonia with a scholarship to finish the $\mathrm{PhD}$ thesis.

\section{References}

[1] Henry HR. Effects of dispersion on salt encroachment in coastal aquifers. Water-Supply Paper 1613-C. US Geological Survey; 1964.

[2] Segol G. Classic groundwater simulations: proving and improving numerical models. Englewood Cliffs, NJ: Prentice-Hall; 1994.

[3] Borisov S, Yakirevich A, Sorek S. Henry's problem - improved numerical results. Ben-Gurion University, Israel;1996, unpublished.

[4] Dentz M, Tartakovsky DM, Abarca E, Guadagnini A, Sánchez-Vila $\mathrm{X}$, Carrera J. Perturbation analysis of variable density flow in porous media. J Fluid Mech, 2006;561:209-35.

[5] Pinder GF, Cooper HH. A numerical technique for calculating the transient position of the saltwater front. Water Resour Res 1970;6(3):87582.

[6] Segol G, Pinder GP, Gray WG. A Galerkin finite element technique for calculating the transient position of the saltwater front. Water Resour Res 1975;11(2):343-7.

[7] Frind E. Simulation of long-term transient density-dependent transport in groundwater. Water Resour Res 1982;5:73-88.

[8] Huyakorn P, Andersen PF, Mercer J, White H. Saltwater intrusion in aquifers: development and testing of a three-dimensional finite element model. Water Resour Res 1987;2(23):293-312.

[9] Voss CI, Souza WR. Variable density flow and transport simulation of regional aquifers containing a narrow freshwater-saltwater transition zone. Water Resour Res 1987;26:2097-106.

[10] Croucher AE, O'Sullivan MJ. The Henry Problem for seawater intrusion. Water Resour Res 1995;31(7):1809-14.

[11] Bues M, Oltean C. Numerical simulations for saltwater intrusion by the mixed hybrid finite element method and discontinuous finite element method. Transport Porous Med 2000;40(2):171-200.

[12] Simpson MJ, Clement TP. Theoretical analysis of the worthiness of Henry and Elder problems as benchmarks of density-dependent groundwater flow models. Water Resour Res 2003;26:17-31. 
[13] Custodio E. Effect of vertical flows inside monitoring boreholes in coastal areas. In: Barrocu G, editor. Proceedings of the 13th saltwater intrusion meeting, Cagliari, Italy; 1994. p. 213-26.

[14] Galeati G, Gambolati G, Neuman S. Coupled and partially coupled Eulerian-Lagrangian model of freshwater-seawater mixing. Water Resour Res 1992(28):149-65.

[15] Benson DA, Carey AE, Wheatcraft SW. Numerical advective flux in highly variable velocity fields exemplified by saltwater intrusion. J Contam Hydrol 1998;34:207-33.

[16] Tellam JH, Lloyd JW, Walters M. The morphology of a saline groundwater body - its investigation, description and possible explanation. J Hydrol 1986;83(1-2):1-21.

[17] Stuyfzand PJ. Behaviour of major and trace constituents in fresh and salt intrusion waters in the Western Netherlands. In: Custodio E, Galofre A. editors. SWIM study and modelling of saltwater intrusion into aquifers, CIMNE-UPC, Barcelona; 1993. p. 143-60.

[18] Barbieri G, Ghiglieri G. Overexploitation and salt water intrusion in the alluvial aquifer of the Rio Foxi Basin, Villasimius (Southern Sardinia). In: Barrocu G editor. Proceedings of the 13th salt-water intrusion meeting, Cagliari, Italy; 1994. p. 353-371.

[19] Oberdorfer JA, Buddemeier RW. Coral-reef hydrology: field studies of water movement within a barrier reef. Coral Reefs 1986;5(1): $7-12$.

[20] Barón A, Calahorra P, Custodio E, Gonzalez C. Saltwater conditions in Sa Pobla area and S'Albufera Natural Park, NE Mallorca Island, Spain. In: Barrocu G, editor. Proceedings of the 13th salt-water intrusion meeting, Cagliari, Italy; 1994. p. 243-57.

[21] Yechieli Y. Fresh-saline ground water interface in the Western Dead Sea area. Ground Water 2000;38(4):615-23.

[22] Sa da Costa AAG, Wilson JL. A numerical model of seawater intrusion in aquifers. Tech Rep 247, Ralph M. Parsons Laboratory, Cambridge MA: MIT; 1979.

[23] Shapiro AM, Bear J, Shamir U. Development of a numerical model for predicting the movement of the regional interface in the coastal aquifer of Israel Tech Rep, Technion Research and Development Foundation Report, Technion, Haifa, Israel; 1983.

[24] Essaid HE. A multilayered sharp interface model of coupled freshwater and saltwater flow in coastal systems: model development and application. Water Resour Res 1990;26(7):1431-54.

[25] Pistiner A, Shapiro M. A model for a moving interface in a layered coastal aquifer. Water Resour Res 1993;29(2):329-40.

[26] Rumer R, Shiau J. Salt water interface in a layered coastal aquifer. Water Resour Res 1968;4(6):1235-47.
[27] Souza WR, Voss CI. Analysis of an anisotropic coastal system using variable-density flow and solute transport simulation. J Hydrol 1987;92:17-41.

[28] Reilly T. Simulation of dispersion in layered coastal aquifer systems. J Hydrol 1990;114:211-28.

[29] Voss CI, Provost A. SUTRA, a model for saturated-unsaturated variable-density ground-water flow with solute or energy transport, Water-Resources Investigations 02-4231, US Geological Survey; 2002.

[30] Sanford WE, Konikow LF. Simulation of calcite dissolution and porosity changes in saltwater mixing zones in coastal aquifers. Water Resour Res 1989;25(4):655-67.

[31] Corbella M, Ayora C, Cardellach E. Dissolution of deep carbonate rocks by fluid mixing: a discussion based on reactive transport modeling. J Geochem Explor 2003;78-79:211-4.

[32] Rezaei M, Sanz E, Raeisi E, Vázquez-Suñé E, Ayora C, Carrera J. Reactive transport modeling of calcite dissolution in the saltwater mixing zone. J Hydrol 2005;311:282-98.

[33] Smith AJ. Mixed convection and density-dependent seawater circulation in coastal aquifers. Water Resour Res 40: W08309, doi:10.1029/2013WR002977.

[34] Bear J. Dynamics of fluids in porous media. Amsterdam: Elsevier; 1972.

[35] Oswald S. Dichteströmungen in porösen medien: Dreidimensionale experimente und modellierungen. PhD thesis, ETH, Zurich, Switzerland; 1999.

[36] Simpson MJ, Clement TP. Improving the worthiness of the Henry problem as a benchmark for density-dependent groundwater flow models. Water Resour Res 2004;40:W01504. doi:10.1029/ 2003WR002199.

[37] IMSL MATH/LIBRARY. FORTRAN subroutine for mathematical applications. Houston TX: Visual Numerics, Inc.; 1997.

[38] Dagan G. Flow and transport in porous formations. Berlin, Heidelberg, New York: Springer-Verlag; 1989.

[39] Dentz M, Carrera J. Effective dispersion in temporally fluctuating flow through a heterogeneous medium. Phys Rev E 2003;68(3):036310.

[40] Cirpka OA, Attinger S. Effective dispersion in heterogeneous media under random transient flow conditions. Water Resour Res 2003;39(9):1257.

[41] Dentz M, Carrera J. Effective solute transport in temporally fluctuating flow through heterogeneous media. Water Resour Res 2005;40(8):W08414. 